\title{
HR outsourcing: the impact on HR's strategic role and remaining in-house $H R$ function
}

Article

Accepted Version

Creative Commons: Attribution-Noncommercial-No Derivative Works 4.0

Patel, C., Budhwar, P., Witzemann, A. and Katou, A. (2019) HR outsourcing: the impact on HR's strategic role and remaining in-house HR function. Journal of Business Research, 103. pp. 397-406. ISSN 0148-2963 doi:

https://doi.org/10.1016/j.jbusres.2017.11.007 Available at https://centaur.reading.ac.uk/74974/

It is advisable to refer to the publisher's version if you intend to cite from the work. See Guidance on citing.

To link to this article DOI: http://dx.doi.org/10.1016/j.jbusres.2017.11.007

Publisher: Elsevier

All outputs in CentAUR are protected by Intellectual Property Rights law, including copyright law. Copyright and IPR is retained by the creators or other copyright holders. Terms and conditions for use of this material are defined in the End User Agreement.

www.reading.ac.uk/centaur 
Central Archive at the University of Reading

Reading's research outputs online 


\author{
Authors: Charmi Patel ${ }^{a}$, Pawan Budhwar ${ }^{b}$, Alissa Witzemann ${ }^{c}$, Anastasia Katou ${ }^{d}$ \\ a International Business and Strategy Group, Henley Business School, University of Reading, \\ RG6 6UD, United Kingdom \\ b British Journal of Management, Work and Organisational Psychology, Aston Business \\ School, Aston University, B4 7ET, United Kingdom \\ c Swiss Re, Mythenquai 50/60, 8022 Zurich, Switzerland \\ d Department of Business Administration, University of Macedonia, 156 Egnatia Street, \\ Thessaloniki 540 06, Greece
}

\begin{abstract}
Past research on HR outsourcing (HRO) has offered conflicting views about its impact on HR's strategic position. This study highlights the processes by which decisions to outsource HR are made, followed by the processes implemented post such decisions and their effect on the HR function. Using a case study approach and semi-structured interviews $(\mathrm{N}=35)$ within a German subsidiary of a US MNC, we provide a framework of HR processes seeking to achieve standardization in terms of harmonization of HR activities across the subsidiary. The findings reveal that the effects of outsourcing on in-house HR showed a decrease in flexibility of the HR function, a slowdown in processing time of transactional HR as well as a decrease in satisfaction and work intensification for HR managers. Further, it remains questionable as to whether the function of HR was able to enhance its strategic position through outsourcing.
\end{abstract}

KEYWORDS: HR Outsourcing, HR Strategic Role, MNCs, Standardization of HR

\title{
INTRODUCTION
}

Outsourcing in general is deemed to considerably impact a firm's performance and is often regarded as a potential source of gaining competitive advantage and a possible strategic opportunity to increase an organisations' competitiveness (Ulrich and Brockbank, 2009).

Operating in today's dynamic and globalized business environment, the function of HR offers several options to enhance gains and opportunities with the purpose of positively contributing towards the overall business performance. Therefore, it seems rational to contend that the outsourcing of HR related tasks play a significant role within organizations and represent an important aspect of the way in which companies operate (Ruth et al., 2015).

In the early 1990s, only tentative forecasts regarding the forthcoming expected growth of HRO were made (Cooke et al., 2005; Vernon et al., 2000). On the contrary, particularly in 
recent years, $\mathrm{HRO}$ has gained considerable attention as it is experiencing significant growth (Cooke and Budhwar, 2009; CIPD, 2009; Lawler and Boudreau, 2009). For example, HR services made up for one-fifth of all outsourcing deals in 2014, according to the UK Outsourcing Index. The index, produced by the business process outsourcing provider Arvato, identified $£ 126$ million of HRO contracts in 2014, with private-sector organisations behind $90 \%$ of contracts signed. This report further highlighted that $77 \%$ of the HR contracts signed in 2014 were new deals, where the function has been outsourced for the first time (Personnel Today, 2015).

Despite these forecasts, many authors highlight the limited availability of literature on the process of decision making of HRO (Cooke and Budhwar, 2009; Lilly et al., 2005). Cooke et al. (2005) claim that the available literature pays little attention as to what specifically is involved in the making of the outsourcing decisions and the way such decisions are implemented and what exactly is their scope. Alewell et al. (2009) point out the need for further research regarding the conditions encompassing the outsourcing decision, which include the structural and contextual setting of the organisation. Likewise, empirical evidence might be needed for the purpose of investigating into the effect of outsourcing in terms of contributing towards HR becoming more strategic. Also, there appears to be a growing need to empirically assess effects of outsourcing HR activities on in-house HR, i.e. the impact of a change in terms of managing the outsourced activity and successfully operating as a multisourced function has not yet been fully explored (Glaister, 2014; Reichel and Lazarova, 2013).

Thus our research makes an attempt to answer the above rasied questions. In particular, the aim of this study is to explore how HRO affects the role of in-house HR function and the rest of the workforce. In doing so, we shed light on the call for this special issue by exploring how companies make the decision to outsource HR? What processes are introduced after the decision to outsource HR has been made? What are the effects of outsourcing on in-house HR function? We begin by discussing the theoretical underpinnings of HRO, by paying special attention to how outsourcing decisions are made, the processes implemented afterwards whilst also analysing the effects on in-house HR. The research methods are then introduced and the findings are presented. The discussion and conclusion is followed by the limitations of the study and recommendations for future research.

\section{THEORITICAL UNDERPINNINGS OF HRO}

\section{How do companies make the decision to outsource HR?}


Amongst the reasons for HRO, the theories of transaction cost economics (TCE) and the resource-based view (RBV) are typically regarded as substantial motivators for outsourcing (e.g. Adler, 2003; Alewell et al., 2009; Cooke et al., 2005; Galanaki et al., 2008; Klaas et al, 2001; Sim, 2012). On accounts of being an interdisciplinary concept drawing on the fields of law, economics and organization theory, to the core of the TCE theory is the question of whether to 'make' or 'buy' the respective products or services (Alewell et al., 2009; Williamson, 2007). With particular reference to the HR function, the literature considers cost reductions as a key motivator when making the outsourcing decision, partly also since this perceived benefit can be documented in numbers and thus certainly providing measurable results (Bharadwaj and Saxena, 2010; CIPD, 2005). In this regard, Lawler et al. (2004) put forth the argument that reductions in HR administrative costs by at least twenty per cent can possibly be expected from outsourcing. Yet, the literature suggests that making the outsourcing decision is contingent upon contextual and organizational factors as well (i.e. indirect costs, company size or the service environment). Hence, TCE does not seem to be universally applicable when seeking to achieve cost reductions through outsourcing (Tremblay et al., 2008). Therefore, reflecting upon and knowing the organization's strategic position appears to be essential (Williamson, 2007). Additionally, TCE might be able to evaluate the option of best value related to its costs, but does not necessarily focus on maximizing the value itself (Cappelli, 2011).

The RBV justifies the concept of outsourcing based on its contribution to the development of an organization's internal core competencies (e.g. Barney, 1991; Glaister, 2014). By increasing their internal strengths and utilizing their unique resources, which are difficult to emulate, organizations are able to gain a competitive advantage (Galanaki et al., 2008). By seeking to maximize this advantage, the RBV can be employed to decide as to whether to perform the activity in-house or externally (Ruth et al., 2015). Generally speaking, non-core activities of the company are typically not considered to represent any competitive advantage. Thus, acquiring the non-core activities externally could enable HR to effectively focus on developing their core activities internally, where they have superior capabilities (Barney, 1991; Lilly et al., 2005; Ulrich, 1996; Ulrich and Brockbank, 2009). Comparable to the TCE, assessing the scope for core and non-core activities also appears to be contingent on contextual characteristics and might be subject to change over time (Cooke et al., 2005; Conklin, 2005; Galanaki et al., 2008). Interestingly, with regard to HR, the majority of HR professionals themselves do not consider the function to play an important administrative role, which seems to confirm the idea of outsourcing non-core transactional activities in 
human resources (CIPD, 2009). Nevertheless, one should bear in mind that outsourcing noncore support functions is essential for maintaining key HR activities, which might potentially result in producing an opposite effect and reducing HR's competitive advantage (Hern and Burke, 2007). By gaining a competitive advantage it may be possible to achieve both cost efficiency as well as generating additional value. Thus, contrary to the TCE, the RBV view seems to take into consideration both the cost and value aspect, but should not be applied as a single criterion in making the outsourcing decision either (Gospel and Sako, 2010).

Research carried out by Sim (2012) found that particularly with reference to HR activities, the outsourcing decision is "largely determined by the need and strategic fit to outsource" rather than by transaction cost theories or the resource-based view (p.710). There is consensus in the literature that when applied strategically, outsourcing can contribute towards strengthening an organization's competitiveness (Conklin, 2005; CIPD, 2005; Glaister, 2014). One may relate this aspect to Ulrich's (1996) model, according to which, by outsourcing, the HR function can redeploy expertise to business partnering. In this connection, outsourcing a company's HR department might contribute towards freeing up HR strategic partners from being involved in transactional tasks, thus enabling the HR to be more strategic and contributing towards adding value to the overall business.

Also, there is a general perception of HR-outsourcing leading to improvements in quality of the outsourced service delivery (Bharadwaj and Saxena, 2010; Pereira and Anderson, 2012). Galanaki et al. (2008) found that perceived quality benefits could be the main driver for making the outsourcing decision. Outsourcing for the purpose of obtaining access to new technologies could potentially offer new opportunities for the HR-function (Adler, 2003; Khanna and New, 2005). By having achieved improvements in technology through outsourcing, one might conclude that this in turn could again lead to cost savings with regard to the overall HR function (CIPD, 2005). Alewell et al. (2009) found that HR decision-making is significantly related to organizational changes such as restructuring decisions, movements of innovations, re-organizing decision making authority, and the introduction of new personnel policies, all of which may implicate new strategic directions.

Klaas et al. (2001) study found that organizational characteristics such as firm size positively influenced the degree of outsourcing. Yet, other sources seem to provide a lack of consensus with regard to the linkage of the firm size on making the outsourcing decision (Alewell et al., 2009; CIPD, 2009). Evidence also suggests that in practice, organization's decisions to outsource are not always rational (Vernon et al., 2000). Hence, with regard to fully understanding the context of how outsourcing decisions are made, Cooke et al. (2005) 
bring forward the argument of there being relatively little and fragmented empirical literature available on this topic.

\section{Processes are introduced after the decision to outsource HR is made}

Literature around implemented processes once the decision to outsource has been made focuses on vendor selection, contract monitoring and management of vendor relations as part of the lifecycle stages of the HRO project. In terms of selecting a potential service provider, cultural similarity between the outsourcing company and the vendor is regarded as a critical factor in the success of outsourcing and functions as a fundamental requirement for a productive relationship (Hern and Burke, 2007; Khanna and New, 2005). This is in agreement with the finding of Cooke et al. (2005) of lower commitment levels of transferred staff in continuing the service delivery, stemming from not having overlapping values between the original and new partner company. Therefore, having comparable HR policies and practices is well-founded criterion for making the vendor selection (Hern and Burke, 2007; Lawler et al., 2004). Vendors' reputation for consistency, and their stability and reliability in operations when seeking to establish a successful outsourcing contract in the long-term are further worth considering. Factors, such as the service level agreements (SLAs) and the expertise within the specific industry are additional criteria for consideration (e.g., Hern and Burke, 2007).

Further, the literature recommends seeking for relationship management competence, which may also help in building an essential partnership with the vendor required in the longterm (Bharadwaj and Saxena, 2010). Moreover, attractiveness and a good reputation of the outsourcing provider are likely to result in increased commitment of the transferring employees (Kessler et al., 1999). Additionally, the management practices of the service provider should have the capacity to be modified to some extent in accordance to the practices of the outsourcing firm (Grimshaw and Miozzo, 2009).

With regard to the selection procedure, elaborating upon the amount and substance of available alternative vendors, combined with the utilisation of a comprehensive and established procedure completed by negotiating with several vendors simultaneously might boost the bargaining position of the outsourcing firm (Lilly et al., 2005). This might result in possibly lower pricing structures offered by vendors. Hence, one might be able to draw the conclusion that vendor availability influences TCE, consequently also influencing the decision-making with regard to HRO.

According to Cooke et al. (2005) maintaining control of the outsourcing relationship is elementary in the outsourcing process. In this connection, fully developed, clearly structured and complex outsourcing contracts positively contribute towards a successful outsourcing 
process by precisely defining the performance requirements and expectations (Conklin, 2005; Grimshaw and Miozzo, 2009). Thus, contract clarity, including for example the positioning of SLAs with documented accountability for service delivery, the determination of expectations of services as well as guaranteed job security seems to be essential (Hern and Burke, 2007). Also, important seems to be the consideration of country specific legal requirements with individual institutional requirements constantly complying with the various laws and regulations (Grimshaw and Miozzo, 2009). Not to be neglected is the contractual documentation in relation to pricing so as to secure staying within the range of agreed costs (Lilly et al., 2005).

Moreover, the literature highlights that an effective change management approach is essential when managing the full outsourcing cycle (Sim, 2012). Wray (1996) outlines the most important aspects to consider when managing the change - namely the tools, processes and people with the latter being the most common aspect independently of which function is being outsourced. Thus, informing the remaining HR community, line managers and employees on the change is regarded as an essential factor in this respect (Hern and Burke, 2007; Khanna and New, 2005). Therefore, when seeking to manage a successful transition it is recommended to actively communicate the additional benefits the new employer is able to offer. Consequently, one could possibly create advantageous spill-over effects counterbalancing and anticipating any negative views.

In this regard, organisations seek to build a strong collective and a diverse leadership team consisting of managers of all relevant functions in order to maximise the skills necessary for a successful change implementation (Hern and Burke, 2007). For building a transition team, a key success factor seems to involve both organisation and vendor equally for each element under consideration. Thus, it is recommended to include members from both sides on all hierarchical levels involved (Khanna and New, 2005). Finally, monitoring and measuring the performance of the outsourced activity as an essential element leads to constantly reviewing the outsourced activity and offers opportunities for improvements (Cooke et al., 2005). Ideally, this should be done by an in-house monitoring team, evaluating the effectiveness by utilising metrics for assessing both the quality of the delivered service and the corresponding costs (Lawler et al., 2004).

\section{Effects of outsourcing on in-house HR}

There seems to be limited literature available in terms of assessing the actual effects of outsourcing on the HR function. Cooke et al. (2005, p.420) present the limited number of thorough, firm-specific and independent studies available in the literature for evaluating "the 
effectiveness of HR outsourcing as a management strategy". Taking into consideration the available studies, research suggests that in addition to centralising human resources, HR managers themselves see HRO as a significant contributor towards an increased effectiveness (Pereira and Budhwar, 2015; Ruth et al., 2015).

Yet, it is questionable as to whether HRO actually enables HR to become more strategic (Cooke et al., 2005; Prouska and Cooke, 2006). In addition, Glaister (2014) contended that having outsourced some of their HR-activities, there was limited options for the HR department to benefit from skill development, all the while laying particular emphasis on cost savings, which resulted in lowering the department's strategic position. Likewise the author found that those HR departments, which decided not to outsource were able to better contribute more towards other parts of the business as well as capable of gaining trust and support of senior managers. Evidence suggests that it might be more difficult for HR to add value to the business by being disunited, eventually leading to a loss in the function's uniqueness (Cooke et al., 2005).

In this connection, Hern and Burke (2007) suggest operating in a combined model of outsourced HR and performing activities in-house as HR functions might potentially lose their identity when solely operating in an outsourced model. A survey conducted by the CIPD (2009) amongst HR professionals further demonstrates contradictions in perceptions regarding the HRO's effectiveness in practice. Results revealed that only a minority considered outsourcing to have enabled them to adopt a strategic role to a great extent, in contrast to over half of all respondents claiming to have adopted to a strategic role only to a limited extent and with over one third who do not consider HR outsourcing as a strategic enabler for the HR function at all. In terms of measuring HR's ability to add value through outsourcing, capturing this value by making use of metrics is recommended in the general HR-literature, may be suggested in order to be able to assess the situation under consideration (Lawler et al., 2004).

However, a universally applicable model or framework to measure the contribution of HRO on the function's strategic position seems to be non-existent in the literature. Overall, Sim (2012) states that despite the extensive emphasis laid on becoming a strategic partner through outsourcing in existing literature, "there is limited disclosure on how HRO is used for the strategic positioning of internal HR delivery" (p.711).

With reference to the effects of HRO on the remaining in-house HR, the available literature suggests that outsourcing leads to an increase in the amount of work for the in-house HR employees. This might possibly be stemming from a more complex situation with the 
additional complication of managing external, often locally dispersed operations. Moreover, with respect to the in-house HR staff occupying a different role through the process of outsourcing, intensification might possibly be experienced on accounts of holding their former job positions and thus having two points of contact (Khanna and New, 2005).

Moreover, limitations of career development opportunities as well as less favourable changes in job contents could negatively affect the in-house HR employees (Cooke et al., 2005). Findings reveal that in some cases HR outsourcing even resulted inter alia in less personal relationships with employees and a decrease in employee morale (Lilly et al., 2005). Sim (2012, p.717) states that holistically speaking, in-house HR is likely to accept the HRO as long as it will not result in any spill-over effects impacting their own job security.

Alternative options possibly include the organisation deciding for some employees to remain in the outsourcing company. This can be achieved through the emergence of new internal roles within the project. These new internal roles might emerge in relation to vendor management. Those responsibilities could potentially entail administering, managing and supervising both the vendor and the outsourcing relationship, which develops subsequently and which might ideally consist of a cross-functional team (Khanna and New, 2005). In conclusion, as aptly pointed out by Glaister (2014), "little is known about how HR outsourcing affects the HR role, competencies and relationships with senior management" and it is difficult to find evidence providing valuable results regarding the effects of HRO on inhouse HR (p.211).

\section{METHODS}

We interviewed 35 HR bounday spanners in terms of HR managers both operational and specialist, project leaders, process experts and sourcing specialists (from the HR service centre) as well managers from the vendor company (see Table 1 for details of research participants). The data were obtained from a German subsidiary of a non-German multinational operating in the private sector and consisting of multiple businesses. During the time of making the decision to outsource the HR activity in 2012, the company had approximately six thousand employees in Germany. In terms of the organizational setting, interaction with top management was prevalent through existing flat hierarchies and empowered organizational structures. In the context of sets of experiences, one might highlight the fact that the respective department already operated in a shared service center model before the outsourcing decision was made. Data collection was conducted over a period of seven weeks and in accordance to the exploratory nature of the study (Silverman, 
2007). Wherever possible, the data were supplemented through secondary documents such as memos of meetings, presentation slides, etc. One of the authors being previous employed by the company and on study break was also able to observe and sit through some important meetings. Though this was not an overtly reflexive ethnographic approach, the author was nonetheless able to closely observe the decision making process through which deliberants came to understand HR outsourcing and its effects.

Prior to each interview, participants were presented with an overview of the study, given details of how the findings were going to be used and assured of their anonymity. The interviews lasted between 90-120 minutes each, and were recorded with participant permission. The interviews were based on HR managerial perceptions and their own HR practice in order to gain insights into the lived experience of boundary spanners as well as vendor management team whilst working through the outsourcing provision. The questions were asked on a range of issues such as the nature of their role in the organizations, the level of resourcing within HR, the motivation behind HRO, the decision-making process, vendor selection characteristics and affect on in-house HR.

With respect to data analysis, applying a coherent methodological bundle as offered by grounded theory was an important underlying aspect for this research, as it complimented the study's research design and also proved to be an inexpensive way of collecting meaningful data (Silverman, 2007). In this connection, we adopted the approach of Glaser (2013), primarily because his suggested data analysis overlapped with this study's analysis, i.e. in terms of a constant comparison of the emerging results. Thus, in order to facilitate the analysis, interviews were audio recorded and transcribed into naturalized and anonymous transcripts immediately afterwards. Upon the participants' request, a copy was sent to them for final verification (Saunders et al., 2009). In line with the overall inductive and explorative research design, analysis and data collection occurred simultaneously (Saunders et al., 2009). Thus, we started this process by identifying the relevant themes and issues that needed to be focused upon and required additional attention (Strauss and Corbin, 2008). We essentially focused on creating categories that are meaningful internally in relation to data as well as being meaningful externally in relation to the other categories (Bryman and Bell, 2011). Eventually, with reference to each research question we came up with a selective code linking together the axial codes (see Table 2 as an example for coding). By constantly comparing the axial codes, we sought to identify the relationships and patterns emerging from the collected data and ensuring theoretical adequacy and integration of the category (Silverman 2007). 


\section{FINDINGS}

\section{Decision to Outsource}

Results indicate that the outsourcing decision was based on the perceived benefits of outsourcing, both strategic and operational, and organizational and contextual characteristics influenced the process of decision making itself. In this connection, perceived strategic benefits for making the outsourcing decision are the outsourcing of non-core activities, categorized here as the RBV, transfer of risks and skipping organizational politics. With regard to the operationally perceived benefits facilitating the making of the outsourcing decision, the participants most frequently mentioned transaction costs in terms of cost reductions.

"I think in general the decision to outsource fits the structural direction the corporate group is heading. Through the desire or the strategy pursuing in increase in efficiency in my opinion I think this is exactly in the idea and the direction being spread by [company name]"- Strategic direction of the MNC

Specialization in terms of gaining knowledge and expertise, quality improvement and the transfer of managerial responsibility can be classified as further operational drivers. Standardization can be related to both strategic benefits in terms of being aligned within the $\mathrm{MNC}$, i.e. by corresponding to the introduction of a global payroll standard, as well as creating a standardized payroll system across the different German legal entities in order to harmonize processes and thus stemming more from operational reasons.

"Um, so in the center we are divided in two teams, one team is HR Ops and the other payroll, and there wasn't a lot of harmony between the two departments" HR Specialist

Contextual characteristics having contributed towards making the outsourcing decision in this case are the decision makers, i.e. involving several different parties and the decision being made at the senior leadership level. Moreover, only having developed the idea of outsourcing while considering all alternatives at hand in a detailed pre-study further contributed towards finally making the outsourcing decision. Also, not classified in a specific category and only mentioned once, was that the German subsidiary obtained a new service center leader and "upheaval came with the new center leader". In addition, prior to the outsourcing, the respective HR activity was already performed centralized in the service center. 
"The previous centre leader could somehow not lead it on a high-level, CRM cases did not go well and there was an upheaval necessary and the first upheaval was [HR Operations leader's name] has been hired and I think there were already considerations when she joined in December 2011 to set up everything completely new"- HR Services Team Leader

\section{Vendor Selection Process and Outcomes}

Extra attention was paid to the vendor selection process itself with an extensive exchange for information and the inclusion of diversity in terms of a cross-functional final vendor decision-making. Vendor selection criteria were partly subject to the organizational and situational factors, which influenced the outsourcing decision-making itself such as the vendor's core competency expertise or alignment of technology in terms of facilitating the aspect of standardization as outlined earlier.

"...there is very tight relationships between the companies. Because you should also see whether your outsourcing provider fits to your company as well"- HR Transition Manager

Special emphasis was laid on the cultural fit of the new provider to the outsourcing organization, inter alia to facilitate the employee transition process and enable the establishment of a mutual partnership, which also proved to be a finding with regard to the processes implemented once the outsourcing decision had been made. Additionally, supporting the process of establishing a partnership between the outsourcing organization and the provider was also emphasized on. In this regard, when establishing contract clarity, diverse functions were also involved.

"But now it's all with the operational team and it's very good to know that the operational team is working together with [provider name] to further improve the processes they have been adding a lot of new processes, modified the old ones. So it's like a post-optimization now which is running good"- HR Process Expert

Findings also revealed that strongly emphasizing the process of communication, once the HRO decision was made, i.e. through multiple communication channels and talking points for works councils on site, delivered a substantially positive effect. Effectively managing the vendor emerged to be an essential aspect, supported, i.e. through on-going mutual exchange and collaboration or knowledge management.

"We already took very much care that we er, establish a good and close partnership like this. Like let's say we call it open doors that we introduced ourselves and said to the vendor whenever you have questions please call us"- HR Process Expert 
As part of an effective vendor management, i.e. by keeping relevant knowledge of the outsourced HR-activity in-house, was the establishment of new roles for two employees who were staying with the outsourcing company from the outsourced department, which the participants dubbed as a successful process all in all.

"They were highly involved and they were actually sub project leaders themselves"HR Manager

Being in line with the established processes of an effective vendor management, strong communications and the new roles of the vendor managers, was also the implementation of change management. Post-outsourcing integration also proved to be a successful process implemented in terms of reinforcing operations in the outsourced model in the long run.

Insert Table 2 about here

\section{In-house HR and Work Intensification}

As can be seen from table 2, regarding the effects of outsourcing on in-house HR, consensus emerged around decrease in flexibility of the HR function. Furthermore, an intensification of work for both remaining in-house staff of the HR services center as well as the HR manager could be observed through the research. A slow down of processing time of administrative requests in relation to the HR-activity outsources, a decrease in the satisfaction of the HR managers and the perceiving of the HR service center as operating within new structures are additional outcomes of outsourcing. Further effects on in-house HR were related to quality improvements of the service delivery in the long term. Also, the effect of the outsourcing on in-house HR in terms of the creation of new roles for existing employees links back to be part of an effective vendor management.

"We have more work through this. We additionally hired someone to upload the files for payroll, full time - that is a full time job and simply an additional headcount that we needed. And this clearly shows that there is actually more work than before. He is literally busy the entire day and the entire month to send documents to [provider name] - from morning "till evening" - HR Service Team Leader

Yet, findings indicate that it remains questionable as to whether HR has improved its strategic position, i.e. as this aspect is dependent on its point of view or a vague perception of how the HR outsourcing strategically contributed. Contradictory findings are presented in terms of the establishment of both an increase and decrease in the transparency of the HR function. 
"But what we definitely notice is that we don't have insight anymore what is internally going on at the external provider. How is it positioned? What is the mentality? When do we talk?"- HR Administrator

Additionally, the HRO led to process improvements and conversely it also complicates the prospects of collaboration, both internally and externally, with the new provider. The HR function not being regarded as 'leaner', in the sense of operating more effectively (even though it experienced a reduction in headcount through the outsourcing) seems to demonstrate another paradoxical finding. The study detects some peripheral findings, namely that the overall employees outside human resources did not feel a difference related to that outsourcing at all in their daily operations.

"I mean we knew where we started back then, for example we didn't have the process harmonized. Today, we have one set of standardized processes we have more than one hundred different inputs for payroll in place"- HR Operations Leader (Germany, Austria and Switzerland)

"I mean the employees just moved from [company name] to [provider name]. So- so that wouldn't make an organization leaner"- Payroll Project Manager

\section{DISCUSSION}

\section{Achieving Standardization through Outsourcing}

Contrary to the literature, achieving standardization through outsourcing found substantial grounding in our case study and hence presents new insights. Yet, aiming to creating uniformity by introducing a global payroll standard across the entire MNC seems to be in line with what has been outlined in the literature in terms of an organization's adaption to a practice based on the motivation to achieve consensus with existing norms (Ansari et al., 2010; Sturdy, 2004). In this context, adapting to the change as a result of modifying internal standards as well as the implementation of this practice appears to represent a political fit and is compatible with the interests of the adopters, potentially due to the fact that the idea of outsourcing was initially developed locally (Ansari et al., 2010). This may be a characteristic of operations within a MNC environment whereby global interests are coordinated without losing the local focus (Koene and Ansari, 2011).

Additionally, the findings also indicate that the global requirement to introduce the new payroll standard exceeded the operational and technical capacity of in-house HR at the time, resulting in forced changes at the local level in order to ensure alignment with the international HR policies and practices. In addition, this global vs. local contradiction seems to prove a challenging institutional complexity for local human resources responding to the 
MNC (Koene and Ansari, 2011). Therefore, the outsourcing decision might potentially have been the consequence of adapting to constant changes that emerge as a challenge to IHRM when operating in a MNC environment (Sparrow et al., 2004). Overall, the strong focus on achieving standardization in this particular case seems to fit well with the thought that making the outsourcing decision is dependent upon the specific context of the organization as outlined in the literature (Sim 2012).

On accounts of being an American MNC operating in Germany, it could potentially have increased the likelihood of being more prone to making the outsourcing decision as transnational organizations appear to experience fewer restrictions in terms of local norms, values and rules regarding the introduction of change (Koene and Ansari, 2011). In addition, making the outsourcing decision in Germany might have been done within the broader, overall framework of global integration and thereby, represents a cultural fit with the MNC's values and practices, as also reiterated by the participants who claimed that making this decision was largely in toe with the corporate direction due to several outsourcing projects and restructurings occurring at that time (Ansari et al., 2010). In this study one might identify the introduction of the organizational practice as representing a technical, cultural and political fit in its adaptation (Oliver, 1992). To give an example, through the outsourcing the organization was able to achieve a technical fit by implementing the same payroll system across all three legal entities in the context of a German-wide standardization.

\section{Data Driven Decision-making}

With regard to what has been stated by participants as a 'pre-study' to outsourcing, which aims to fully explore all alternatives at hand and in the context of all perceived alternatives available, the outsourcing decision was evaluated cross-functionally with a particular focus on possible cost savings. Thus, as claimed by senior HR Manager that "it was a very fact-driven decision making", the prevalent case seems to demonstrate a rational decision-making approach by corresponding to the most effective option and optimal choice in line with the environment they are operating in (Ansari et al., 2010; Williamson, 1979). It gives the impression that the decision-making process has been divided into a series of stages. By having effectively worked through the stages and having systematically applied 'sensemaking', this potentially led to the prevalent evidence-based decision-making approach (Weick, 2012). Therefore, although the existing literature illustrates how outsourcing decisions are not made rationally by organizations, this study suggests the contrary.

As in line with the institutional theory and as also seen to be the case when an MNC operates from a polycentric approach, the local HR team started the change by investigating 
into the idea, developing a concept and proactively seeking support from the top management and the headquarter (Dowling et al., 2013). Yet, this seems to contradict all existing evidence that HR itself usually only gets involved in the outsourcing process during the realization phase and not during the actual decision making process and that outsourcing decisions are purely made by senior management. Hence, one might potentially conclude that the MNC's country tailored leadership has contributed towards effectively recognizing the need for and investigating in the local change of the HR activity (Brewster e al., 2011).

We also found that the shared HRO (SHRO) played a vital role in supporting and promoting the outsourcing decision amongst the top management. Hence, this may be in accordance with the crucial need for today's organizations to have a business-oriented SHRO seeking to create company specific value by focusing on the corporate strategy (Lawler and Boudreau, 2009; Ulrich and Brockbank, 2009). Drawing from the evidence-based research with reference to the spectrum of diversity, cross-functional decision-making by integrating individuals from different levels, functions and regions (i.e. by including the sourcing department), seems to have been beneficial in terms of offering a comprehensive evaluation of outsourcing from different perspectives, as heterogeneity and inter-group variation helps in critically evaluating the decision making (Cox, 1991).

\section{HRO Logic and Institutional Context}

Given frequent multinationals interventions tend to interfere with local institutional arrangements, potentially resulting in unexpected influences on the implementation of the change, appropriate and extensive communication seem to have prevented any obstacle in the context of Germany's strong role of institutional voids such as the works councils (Grimshaw and Miozzo, 2009; Koene and Ansari, 2011). Here, perhaps the extensive communication and detailed consolidation of institutions might be attributable to the fact that outsourcing of the payroll function represents an increased risk of compliance as the external services provider receives highly confidential personal data.

It therefore gives the impression that in order to facilitate the transition, making use of a strong change management approach proved to be successful. Here, future benefits for the employees in order to counteract negative effects of the outsourcing and in order to promote the attractiveness of the vendor have been actively communicated from the organization side and supported by the on-site presence of the vendor. In addition, including the respective employees in the change i.e. in the definition of processes as well as seeking to have conversations with and offering change management trainings for remaining in-house HR, appeared to counteract future uncertainty and decreases in motivation (Hayes, 2014). The 
effective outcome of change management seems to have found substantial support of the diverse composition of the project team through the reflection of different views (Wright et al., 2011).

Counteracting a potential pitfall and one of the greatest risks of outsourcing primarily the potential loss of local knowledge and capability, new roles for employees of the respective HR activity who have not been outsourced and who remained with the organization have been created, ensuring that at least some of the outsourced expertise stays in-house (Lawler et al., 2004). According to participants and also as suggested in the literature this proved to be a key success factor here and thus may be recommended when conducting outsourcing in terms of effective knowledge management. In addition, it could also result in the opportunity for the organization for claiming internal expertise towards the provider in the form of a control mechanism (Christopher and Tanwar, 2012).

\section{Structuration and Vendor Management}

Findings of this study further demonstrate that in terms of effectively managing the vendor, building a relationship through structural integration between the company and the provider proved to be very beneficial. In the case under consideration, this has been facilitated by ensuring collaboration between both organizations at different levels, such as through seeking to build a relationship bottom up whilst ensuring that both parties are equally involved in work-streams in terms of shared responsibility as well as on the leadership level by conducting regular personal meetings and teambuilding activities. In this respect, participants of being highly effective considered the establishment of a transition team consisting of diverse roles, like the project manager, HR manager and vendor managers. Furthermore, the organization was able to influence and alter the vendor's HR policies and practices, regarding compensation and benefits and adjusting contracts that were to be offered. This proved to be advantageous and reflects what has been recommended in successful vendor management in existing literature. One might potentially argue that the fact that all employees accepted the new contract of the provider firm and no attrition, whilst also agreeing to perform their role until the actual transition happened, might be due to a strong

psychological contract, the fact that the outsourcing process was of collaboration (assimilating the employees into the change) and also because of clear and honest communication, resulting in a fair treatment of employees (Cooke and Budhwar, 2009).

\section{Changes to In-House HR Function}

One striking result of this study is the notion of decreased flexibility of the function of HR. This seems to particularly stem from having to strictly follow the newly defined 
processes between the HR service center, the HR manager and the provider. Yet, this decrease of flexibility does not seem to find any grounding in the literature, as an increase in flexibility is generally regarded as a perceived benefit of HRO. One might interpret this as possible reductions in competitiveness, as organizations best performing HR are commonly also characterized by flexibility and agility (Benko and Volini, 2014).

Results of this research further suggest a work-intensification for in-house HR, for both the remaining employees of the HR service center as well as the HR managers. Assessing the work intensification for the HR service center employees, this may be stemming from a more complex situation by now additionally having to manage the externally outsourced and locally dispersed HR activity. Moreover, before operating in the outsourced model and having had the payroll included in the HR service center, HR operations employees have been contacted solely regarding HR operational-related requests. In the current situation, every transactional HR inquiry, including all payroll related tasks, is being channeled through the HR operations department in the service center, which will then be forwarded to and coordinated with the new provider. In contrast to the previous situation, this implies not having the option for a direct contact between the HR manager and the outsourced activity, thus intensifying the effort involved in the collaboration and communication required from the service center employees. This reflects that the remaining in-house HR department now representing two points of contacts.

What we did not come across in the literature so far is the fact that tasks, which belong to the scope of the outsourced HR activity, are now being brought back in-house due to inefficient and drawn-out sequences of processes. These tasks are now being performed by the in-house HR and thus automatically increasing the amount of work to cope with. This intensification of work seems to be supported by the hiring of an additional headcount solely responsible for forwarding administrative work to the external provider. So, despite a reduction in headcount through the transition, the headcount of the remaining HR operations part seemed to have increased through the add-on (Khanna and New, 2005).

It gives the impression that the changes in job contents for the employees of the HR service center in terms of a less favorably work intensification seems to have negatively affected their overall attitude towards work and may perhaps impact the employee engagement. This again demonstrates how outsourcing may possibly negatively affect employee morale (Lilly et al., 2005). Likewise, the work intensification for the HR managers, as some payroll expertise is now required from their role on-site regarding certain requests seems to represent a contradicting finding. In the existing literature, HRO is held responsible 
for enabling the HR managers to be relieved of the administrative tasks and subsequently being able to focus more on the business needs.

Additionally, a factor that is reflected in the literature, which this study highlights is a slowdown of processing time of transactional work related to the outsourced activity. This could be explained by the clear definition of processes to be followed rigidly and the decreased tolerance towards flexibility outside a defined process sequence as well as due to the fact that all requests are now solely being channeled through the remaining HR operations employees and thus protracting communication flows and efficient processing. Also, previously the execution of both HR-activities in-house and identifying and solving upcoming problems easier and quicker when not being geographically separated, potentially also increased the perception of a slow down of processing time (Lawler et al., 2004). However, this result represents contradictory findings vis-à-vis the existing literature, which states that outsourcing should achieve a faster response rate in relation to transactional HR.

Interestingly, the study highlights that the HRO rather led to a decrease in satisfaction for the HR managers. It gives the impression that this aspect potentially results from the study's other findings, i.e. the work intensification for the HR managers, a slowdown in the processing time of transactional HR related to the outsourced activity as well as the perceived decrease in flexibility of the HR function. In addition, participants' answers indicate that in particular the decrease in satisfaction of the HR mangers could possibly be related to an automatic decrease in the quality of the service delivery in the beginning of the outsourcing delivery, as outlined in research question one.

Further, assessing the effect of the outsourcing on in-house HR, the study's contradicting results regarding the impact on transparency of the HR department may be explained as follows. The perceived increase in transparency seems to be a result of operating now with clearly defined processes providing the in-house HR team with guidance as to how to follow them contrary to the seemingly more off-the-record, previously internal carrying out of HR transactional tasks. Yet, the stated decrease in transparency of the HR department seems to be due to the limited insight into how the outsourced activity is now being performed within the new provider including their internal processes.

\section{Strategic Role of HR}

Through the outsourcing, the HR service center seems to benefit from the perceived new structures of the department. Particularly, now HR operations and payroll are indeed being seen as two different activities, whereas earlier they were regarded by the HR community and the overall organization's employees as one department, thus leading to 
confusion and perceived complexity. Thus, although this case may not represent a complete redesigning of the HR function, it seems that outsourcing has brought clarity regarding HR's structure and finds consensus in the literature (Ulrich, 2014). A substantive effect on the remaining in-house HR may be the creation of new alternative roles for employees staying with the company. As in this case, the vendor managers now have a direct reporting line to the department leader through the outsourcing and they experience changes in job roles in terms of now being in charge for administering, managing and supervising the collaboration with the vendor.

The study suggests that the outsourcing did not seem to increase the capacity for the HR function to operate more strategically. Linking with what has been already outlined in relation to an intensification of work for the in-house HR, as the outsourcing did not automatically reduce the amount of administrative processes, as well as the decrease in flexibility, it gives the impression that contrary to what has been outlined in the literature, the outsourcing did not free up internal resources in order to enable HR to focus more on strategic work (CIPD, 2005; Ulrich and Brockbank, 2009). Thus, it remains questionable as to whether HR is now a more strategic business-driven advisor. Results of this study correspond with the findings of a CIPD (2009) survey in which only a minority of the HR-respondents regarded the HRO as having allowed HR to adopt a strategic role to a great extent. Therefore, this study's findings seem to also be in line with what has been outlined by Cooke et al. (2005), i.e. "outsourcing HR to enable an in-house HR department to take on a more strategic role remains largely an aspiration rather than a reality" (p.422).

Yet, with reference to the assessment as to whether HR has become more strategic, as participants pointed out, contrary to what is common practice in most organizations and although having operated with a shared service center, the HR manager has always been highly involved in transactional HR activities. In this connection, participants of this study stated that having a strong change management approach from the beginning when already started to operate in the service center model would have been supportive. Thus, defining and communicating a vision in transforming HR towards being more strategic at that time could have perhaps improved today's perceptions of the effectiveness of outsourcing in terms of making HR more strategic (Hayes, 2014; Glaister, 2014). This confirms the available literature that the effectiveness of HR outsourcing also seems to be contingent upon the individual organizational characteristics.

We also found that there was a tendency of in-house employees to constantly and individually compare the new service with the situation prior to outsourcing and this might 
potentially have influenced the overall results (Cooke et al., 2005). Hence, as change generally upsets the balance of power, we had the impression of a rather negative opinion about the outsourcing practice of the in-house HR staff and one may potentially also interpret that with uncertainty regarding their own job security (Sim, 2012). In addition, as outlined by Truss et al. (2002; p.39), "HR functional roles are located within a complex and dynamic social setting and depending on each other's expectations" and thus one might argue that the in-house HR might potentially have different expectations from the outsourcing practice and thereby not resulting in a decrease in flexibility and intensification of work.

Finally, interpreting the peripheral finding, the remaining HR community other than the HR managers and the HR services center employees and the overall employees, seemingly not having noticed the outsourcing at all could be linked to the fact that the activity has already been decentralized before by operating in the shared service center environment.

\section{LIMITATIONS AND FUTURE RESEARCH}

This study draws conclusions from one single MNC, and the case organization observed operates in a combined model of outsourced HR and performing activities in-house, and thereby does not represent a complete extensiveness in the adaption of the practice for the full HR department. Therefore, the findings need to be treated with caution as the specific case precludes generalizability. Though we tried to gather multi-stakeholder views by interviewing HR service center employees, HR managers/team as well as vendor employees, future studies should look at triangulating data across a range of research methods. The limitations associated with a cross-sectional study are also to be recognized, and it would be useful for future research to develop a longitudinal approach that traces HR's development and changing position within the organization. For example, as seen in this study, making the outsourcing decision is also influenced by the organization's context and current situation. Thus, it may be of advantage to assess under which contextual circumstances outsourcing decisions are most beneficial. Besides understanding how companies make the outsourcing decision, likewise one might seek to acquire insight into how organizations make the decision to perform HR in-house and how and to what extent the processes implemented after that decision has been made are likely to alter the HR function. Notwithstanding these limitations, the study adds richness to an understanding of the complexities of HRO and its impact on the strategic role of the HR function.

\section{IMPLICATIONS FOR PRACTICE}


Reflecting upon the wider scope of this study, one may be able to relate the findings to the general challenges in IHRM. In this case both the manner in which the outsourcing decision was made as well as the processes initiated afterwards are somewhat linked to the scope of operating within an international environment within the MNC structure. This also seems to correlate with seeking the optimum and most efficient way of structuring the German subsidiary in terms of its HR function in order to reach the targets by fulfilling corporate requirements. Additionally, the study outlines the difficulty in determining as to what extent HR activities should be handled in-house as opposed to being outsourced. In addition, as the findings question the effectiveness of the HRO to some degree, it remains somewhat unclear as to under which conditions HRO may be most effective. Considering the role of the HR function in the context wider than this study, the authors got the impression that to a great extent the function of human resources is still being regarded as being highly transactional and less effective in terms of contributing towards the overall aims of the business. Referring to Evans et al. (2011), one might potentially classify the role of human resources in this case as realigning HRM, as there seems to be a focus on change and generating external and internal fit in order to aim at contributing towards the MNCs strategy in the future and realigning the current direction of HR.

\section{References}

Adler, P.S. (2003). Making the HR outsourcing decision. MIT Sloan Management Review, Fall, pp.53-60.

Alewell, D., Hauff, S., Thommes K. and Weiland K. (2009). Triggers of HR outsourcing decisions - an empirical analysis of German firms. The International Journal of Human Resource Management, 20(7), pp.1599-1617.

Ansari, S.M., Fiss, P.C. and Zajac, E.J. (2010). Made to fit: How practices vary as they diffuse. Academy of Management Review, 35(1), pp.67-92.

Barney, J. (1991). Firm resources and sustained competitive advantage. Journal of Management, 17(1), pp.99-120.

Benko, C. and Volini, E. (2014). What it will take to fix HR. Harvard Business Review. Bharadwaj, S.S. and Saxena, K.B.C. (2010). Service providers' competences in Business Process Outsourcing for delivering successful outcome: An exploratory study. Vikapla, 35(3), pp.37-53.

Brewster, C., Sparrow, P. and Vernon, G. (2011). International Human Resource Management. London: CIPD.

Bryman, A. and Bell, E. (2011). Business Research Methods. Oxford University Press: New York.

Cappelli, P. (2011). HR sourcing decisions and risk management. Organizational Dynamics, 40(4), 310-316.

Christopher, D. and Tanwar, A. (2012). Knowledge management in outsourcing environment: People empowering people. The IUP Journal of Knowledge Management, 10(2), pp.61-86. 
CIPD (2005). Outsourcing human resources - A framework for decisions. London: CIPD.

CIPD. (2007). Talent management: Research insight. London, CIPD.

CIPD (2009). HR outsourcing and the HR function Threat or opportunity? Survey Report June. London: CIPD.

Conklin, D.W. (2005) Risks and Rewards in HR Business Process Outsourcing. Long Range Planning, 38(6), pp.579-598.

Cooke, F.L. and Budhwar, P. (2009). HR Offshoring and Outsourcing: Research Issues for IHRM. In P. Sparrow (Ed.) Handbook of International HR Research: Integrating People, Process and Context. London: Blackwell.

Cooke, F.L., Shen, J. and McBride, A. (2005). Outsourcing HR as a competitive strategy? A literature review and assessment of implications. Human Resource Management, 44(4), pp.413-432.

Corbin, J. and Strauss, A. (2008). Basics of qualitative research: Techniques and procedures for developing grounded theory. Thousand Oaks: Sage publications.

Cox, T. (1991). The Multicultural Organization. Academy of Management Review, 5(2), pp.34-47.

Dowling, P. J., Festing, M. and Engle, R. (2013). International Human Resource Management. London: Thompson learning.

Evans, P., Pucik, V. and Bjorkman, I. (2011). The global challenge: Frameworks for International Human Resource Management. New York: McGraw Hill.

Galanaki, E., Bourantas, D. and Papalexandris, N. (2008). A decision model for outsourcing training functions: distinguishing between generic and firm-job-specific training content. The International Journal of Human Resource Management, 19(12), pp.2332-2351.

Glaister, A.J. (2014). HR outsourcing: The impact on HR role, competency development and relationships. Human Resource Management Journal, 24(2), pp.211-226.

Glaser, B.G. (2013). Staying open: The use of theoretical codes in GT. The Grounded Theory Review, 12(1), pp.3-8.

Gospel, H., \& Sako, M. (2010). The unbundling of corporate functions: the evolution of shared services and outsourcing in human resource management. Industrial and Corporate Change, 19(5), 1367-1396.

Grimshaw, D. and Miozzo, M. (2009). New human resource management practices in knowledge-intensive business services firms: the case of outsourcing with staff transfer. Human Relations, 62(10), pp.1521-1550.

Hayes, J. (2014). The Theory and Practice of Change Management. New York: Palgrave MacMillan.

Hern, C. and Burke, R.J. (2007). Outsourcing; enhancing the experience of transitioned employees. The Journal of Industrial Relations and Human Resources, 9(2), pp.2948.

Kessler, I., Coyle-Shapiro, J. and Purcell, J. (1999). Outsourcing and the employee perspective. Human Resource Management Journal, 9, pp.5-19.

Khanna, S. and New, J.S. (2005). An HR planning model for outsourcing. Human Resource Planning, 28(4), pp.37-43.

Klaas, B.S., McClendon, J. and Gainey, T.W. (2001). Outsourcing HR: The impact of organisational characteristics. Personnel Psychology, 52(1), pp.113-136.

Koene, B. and Ansari, S. (2011). Institutional change and the multinational change agent. A study of the temporary staffing industry in Spain. Journal of Organisational Change Management, 24(4), pp.511-531. 
Lawler III, E. E., Ulrich, D., Fitz-Enz, J., \& James Madden, V. (2004). Human resources business process outsourcing: Transforming how HR gets its work done. John Wiley $\&$ Sons.

Lawler, E.E. and Boudreau, J.W. (2009). What makes HR a strategic partner? People and Strategy, 32(1), pp.14-22.

Lilly, J., Gray, D. and Virick, M. (2005). Outsourcing the human resource function: Environmental and organizational characteristics that affect HR performance. Journal of Business Strategies, 22(1), pp.55-73.

Miozzo, M. and Grimshaw, D. (2011). Capabilities of large services outsourcing firms: The "outsourcing plus staff transfer model" in EDS and IBM. Industrial and Corporate Change, 20(3), pp.909-940.

Oliver, C. (1992). The antecedents of deinstitutionalization. Organization Studies, 13(4), pp.563-588.

Pereira, V. and Anderson, V. (2012). A longitudinal examination of HRM in a human resources offshoring (HRO) organization operating from India. Journal of World Business, 47(2), 223-231.

Pereira, V. and Budhwar, P. (2015). HRM and firm performance: the case of the Indian IT/BPO industry in Business models and people management in the Indian IT industry. Malik, Ashish and Rowley, Chris (ed.) Working in Asia. Abingdon (UK): Routledge.

Prouska, R. and Cooke, F.L. (2006). Global trends and the challenges to the HR profession. Human Factor, 1(2), pp.17-25.

Reichel, A., \& Lazarova, M. (2013). The effects of outsourcing and devolvement on the strategic position of HR departments. Human Resource Management, 52(6), 923-946.

Ruth, D., Brush, T.H. and Ryu, W. (2015). The use of information technology in the provision of HR compensation services and its effect on outsourcing and centralization. Journal of Purchasing \& Supply Management, 21, pp.25-37.

Saunders, M., Lewis, P. and Thornhill, A. (2009). Research Methods for Business Students. Harlow: Pearson.

Sim, C.S. (2012). Strategic human resource outsourcing: An experience of an MNC in Malaysia. In: $2^{\text {nd }}$ International Conference on Management, Langkawi, Malaysia. 11-12 June, pp.710-722.

Silverman, D. (2007). Doing qualitative research: A practical handbook. SAGE Publications Limited.

Sparrow, P., Brewster, C. and Harris, H. (2004). Globalizing Human Resource Management. London: Routledge.

Strauss, A. and Corbin, J.M. (2008) Basics of Qualitative Research: Techniques and Procedures for Developing Grounded Theory. SAGE Publications Limited.

Sturdy, A. (2004). The adoption of management ideas ad practices: Theoretical perspectives and possibilities. Management Learning, 35(2), pp.155-179.

Tremblay, M., Patry, M. and Lanoie, P. (2008). Human resources outsourcing in Canadian organizations: An empirical analysis of the role of organizational characteristics, transaction costs and risks. The International Journal of Human Resource Management, 19(4), 683-715.

Truss, C., Gratton, L., Hope-Hailey, V., Stiles, P. and Zaleska, J. (2002). Paying the piper: Choice and constraint in changing HR functional roles. Human Resource Management Journal, 12(2), pp.39-63.

Ulrich, D. (1996). The Human Resource Champions: The Next Agenda for Adding Value and Delivering Results. Boston: Harvard Business Review Press. 
Ulrich, D. and Barney, J.B. (1984). Perspectives in organizations: Resource dependence, efficiency, and population. Academy of Management Review, 9(3), pp.471-481.

Ulrich, D. and Brockbank, W. (2009). The HR business-partner model: Past learning and future challenges. People and Strategy, 32(2), pp.5-7.

Vernon, P., Philips, J., Brewster, C. and Ommeren, J. (2000). European Trends in HR Outsourcing. Report for William M. Mercer and the Cranfield School of Management.

Weick, K.E. (2012). Organized sensemaking: A commentary on processes of interpretive work. Human Relations, 65(1), pp.141-153.

Williamson, O.E. (1979). Transaction cost economics: The governance of contractual relations. Journal of Law and Economics, 22(2), pp.233-261.

Williamson, O.E. (2007). Transaction cost economies: An introduction. Discussion Paper. www.economics ejournal.org/economics/discussionpapers/2007$3 /$ count $+\& \mathrm{~cd}=4 \& \mathrm{hl}=\mathrm{en} \& \mathrm{ct}=\mathrm{clnk} \& \mathrm{gl}=\mathrm{de}$.

Wright, P.M., Stewart, M. and Moore, O.A. (2011). The 2011 CHRO challenge: Building organizational, functional and personal talent. Cornell Centre for Advanced Human Resource Studies.

Wray, G.N. (1996). The role of human resources in successful outsourcing. Employment Relations Today, 23(1), pp.17-23.

\section{Table 1: List of Participants}

\begin{tabular}{|lll}
\hline & Job Title & Number of Interviews \\
& HR Operations Leader, Germany & 1 \\
& Austria and Switzerland & \\
& Analyst Project & \\
Managers & 4 \\
& HR Managers & \\
& Payroll Projects Managers & 2 \\
& HR Administrators & 3 \\
Outsourcing Company & HR Process Experts & 5 \\
& HR Services Team Leaders & 3 \\
& HR Specialists & 4 \\
& Sourcing Specialists Europe & 1 \\
& Senior HR Manager Germany and & 1 \\
& Europe & \\
& Head HR Consultant & 1 \\
Vendor Company & HR Transition Managers & 3 \\
& BPO Managers & 3 \\
Total & $\mathbf{3 5}$
\end{tabular}




\section{Table 2: Coding Framework for Effects of HR Outsourcing on Strategic Role of HR Function}

\section{Axial codes}

Decrease in flexibility

Work intensification for $\mathrm{HR}$ services

Work intensification for HR managers

Slow down of processing time

Decrease in satisfaction of HRMs

New structure of HR services

\section{Summary of most relevant open codes}

No integrated payroll department; three party involvement complicating processes; non-flexibility of the provider; depending on provider's input; geographically dispersed; strict adherence to processes; limited direct communication; additional processes of provider

Payroll expertise required of HR operations; increased payroll related responsibilities; bringing payroll tasks in-house; less efficient task distribution; introduction of additional steps; increased effort required from in-house HR; extensive effort required until smooth-running of project; additional $\mathrm{HC}$ needed for HR service center.

Involvement from HRMs in operational/admin activities

Requirement to strictly following processes; no direct contact between HRMs and payroll; longer processes in duration; process adjustment difficulties; longer communication processes

Slow down of processing time; communication difficulties; several on-going process changes; provider's systems not aligned; inconsistency in payroll; HR Ops needs to follow official process without exceptions; need to stick to processes; quality reductions in the beginning; increased number of internal processes; limited contact opportunities between HRMs and payroll

HR function has been 'tightened' up; functional reduction to only HR Ops; clear separation of work; clear structure of HR services now; better fit to overall organization structure

\section{Example quotations of participants}

"(HR) has it easier before, because we didn't stick to the official way of how it should be".

"we have more work through this. Additionally, hired someone to upload the files for payroll, full time- that is full time job and simply an additional headcount that we needed. And this clearly shows that there is actually more work than before. He is literally busy the entire day and the entire month to send documents to (provider name)- from morning till evening".

"It's a lot actually what HR operations has to do and the HR manager. It was a change, before I gave it the payroll and the did it. Now [provider name] says we're not [company name] anymore and you yourself also need to have some expertise"

"Very important, as time plays a crucial role here. And everything, what I outsourced is obviously also a time factor. That is obviously not as fast as if the people are sitting next to me or as if I can just quickly walk there"

"Also the communication itself between the HRMs and the payroll is a bit limited and that also makes it difficult to get in contact with the payroll. Or at least people perceive it as being more difficult to reach them"

,... the function of HR has been tightened up in general....HR outsourcing some positive effects as well on the overall organization, some "healing" effects" 
HR more strategic?

Questionable whether HR more strategic now; payroll needs to be done right 'anyway'; depending on point of view; global level

would see HR as being more strategic; no difference for Germany HR community; matter of how you sell the project internally;

HRMs do not see real advantage of one point of contact; "seen as making it more complicated"

Quality increase in delivery

More professionally time-wise + content-wise; service providing nature now; better system now; accuracy increase; increase in speed due to processes

Increase in transparency

Less insight into external payroll processes; no insight to provider's system

Process improvements

Defined + clear processes; agile processes to react to changes; rigor in processes; strict processes make it less complicated

New roles for existing

employees

Vendor managers; bottom-up involvement of subject matter experts; posting of project management positions; best performing English-speaking employees; sub project leaders

Complication of

collaboration

HR not seen as being 'leaner'
Now geographically dispersed; difficulties due to centralization and functional separation; unclear responsibilities regarding tasks; complicated processes

Not leaner process-related; same number of people in charge of payroll; overall still being regarded as 'one' (HR Ops and payroll)
"But it is all a matter of perception if you would ask colleagues they would rather say no as they do not buy fully into the model" HR services everybody knows how it works right now and everybody understood the process and how everything worked and this also increased the accuracy and the speed um, yea of the different transactions"

"But what we definitely notice is that we don't have insight anymore what is internally going on at the external provider. How is it positioned? What is the mentality? When do we talk? "

"I mean we knew where we started back then, for example we didn't have the process harmonized. Today, we have one set of standardized processes we have more than one hundred different inputs for payroll in place"

"Yea we see ourselves as something like vendor managers so therefore we are of course still in contact with them to currently discuss the things and um, of course keep the partnership um, very closely"

"Um, it is outsourced but at the moment it is a bit vague, er, from which sides, er, also from the payroll side, "who is actually responsible for which tasks?"

"I mean the employees just moved from [company name] to [provider name]. So- so that wouldn't make an organization leaner" 